\title{
Ax ACCOUNT OF THE EXPERIMENTS MADE Ix MULHOUSE, GERMANY, BY A COMMITTEE OF THE INDUSTRIAL SOCIETY OF THAT CITY, ON A CORIISS STEAM ENGINE, TO DE'TERMINE ITS ECONOMIC PERFORMANCE WITH AND WITHOUT STEAM-JACKETING.
}

By Chief Engineer Isherwood, U. S. Tavy. (Continued from page 371.)

\section{Results OF THE EXPERIMENTS.}

In all the experiments except $H, I, J$ and $K$, the cut-off was fixed, so that the measure of expansion with which the steam was used did not vary during each experiment. In experiments $H, I, J$ and $h$, the cut-off was variable by the action of the governor, but the uniformity of the load and the steadiness of the steam pressure restricted the point of cutting off within very narrow limits.

The economy of the performance in the different experiments may be compared for the total horse-power and for the net horse-power developed by the engine, the units of heat consumed per hour per horse-power being taken as the measure of the economy. The total horse-power represents the entire dynamic effect of the steam, including overcoming the external load and the internal resistance of the back pressure against the piston and all the friction resistances. The net horse-power represents that portion of the entire dynamic effect of the steam which is expended in overcoming the external load and the friction of that load; it is exclusive of the dynamic effect expended in overcoming the internal resistance of the back pressure against the piston, and of the friction of the unloaded engine. The net horsepower is the only portion of the dynamic effect of the steam which is commercially valuable, and its greater or less cost is the only economic problem in this relation to the user of steam power.

Of the economy due to the different measures of expansion with which the steam was used. In the case of experiments $A, B$ and $C$, where there was no steam present in the cylinder jackets or piston, the steam was expanded 12.3978 times in experiment $A$, and 7.9033 times in experiments $B$ and $C$. Now as experiment $C$ was a repetition of 
experiment $B$, the mean of the economic results of the two may be taken as the cost of the power in units of heat consumed per hour.

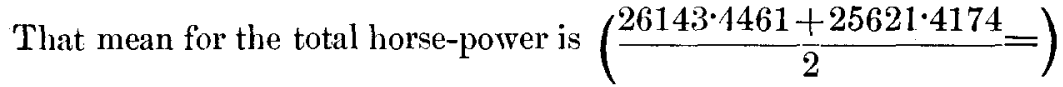
25882.4317 units. The cost of the total horse-power in experiment $A$ was 26731.8267 units of heat consumed per hour; hence, for the total horse-power under the conditions of these experiments, expandthe steam 12.3978 times, gave $\left(\frac{26731 \cdot 8267-25882 \cdot 4317 \times 100}{25882 \cdot 4317}=\right)$ $3 \cdot 2817$ per centum less economy than expanding it $7 \cdot 9033$ times.

Making the same comparison for the net horse-power, we have for its cost, as the mean of the experiments $B$ and $C$,

$$
\left(\frac{32440 \cdot 2587+31735 \cdot 4286}{2}=\right)
$$

32087.8436 units of heat consumed per hour, the steam being expanded 7.9033 times. In experiment $A$, in which the steam was expanded $12 \cdot 3978$ times, the cost of the net horse-power was 37285 -6168 units of heat consumed per hour; hence, for the net horsepower under the conditions of these experiments, expanding the steam $12 \cdot 3978$ times gave $\left(\frac{37285 \cdot 6168-32087 \cdot 8436 \times 100}{32087 \cdot 8436}=\right) 16 \cdot 1986$ per centum less economy than expanding it 7.9033 times.

In the case of experiments $E$ and $F$, where steam was present in the cylinder jackets, but not in the piston, the steam was expanded 10.8259 times in experiment $E$, and $5 \cdot 7037$ times in experiment $F$. The cost of the total horse-power in experiment $E$ was $19452 \cdot 7617$ units of heat consumed per hour, and in experiment $F 20230 \cdot 7613$ units; hence, for the total horse-power under the conditions of these experiments, expanding the steam 10.8259 times gave

$$
\left(\frac{20230 \cdot 7613-19452 \cdot 7617 \times 100}{20230 \cdot 761: 3}=\right)
$$

3.8456 per centum more economy than expanding it $5 \cdot 7037$ times.

Making the same comparison for the net horse-power, we have for its cost in experiment $E 25542 \cdot 3868$ units of heat consumed per hour, and in experiment $F 24223 \cdot 0957$ units; hence, for the net horsepower under the conditions of these experiments, expanding the . steam $10 \cdot 8259$ times gave $\left(\frac{25542 \cdot 3868-24223 \cdot 0957 \times 100}{24223 \cdot 0957}=\right) 5 \cdot 4464$ per centum less economy than expanding it $5 \cdot 7037$ times. 
In the case of experiments $G, H, I, J, K$ and $L$, where steam was present in the cylinder jackets and in the piston, the steam was expanded a different number of times in each experiment, varying from 5.7037 to 10.8259 times. The following table shows the relative costs of the total horse-power and of the net horse-power for these different measures of expansion in units of heat consumed per hour, assuming for unity the cost of the horse-power with the steam expanded $5 \cdot 7037$ times.

\begin{tabular}{|c|c|c|c|}
\hline $\begin{array}{l}\text { Designation } \\
\text { of experiment. }\end{array}$ & $\begin{array}{l}\text { Number of times } \\
\text { the steam was } \\
\text { expanded. }\end{array}$ & $\begin{array}{r}\text { Relative costs of the } \\
\text { of heat consu }\end{array}$ & $\begin{array}{l}\text { horse-power in unit } \\
\text { ned per hour. }\end{array}$ \\
\hline $\boldsymbol{L}$. & $5 \cdot 7037$ & $\begin{array}{c}\text { Total horse-power. } \\
1.0000\end{array}$ & $\begin{array}{c}\text { Net horse-power. } \\
1.0000\end{array}$ \\
\hline $\boldsymbol{K}$ & $5 \cdot 8670$ & 0.9639 & 0.9649 \\
\hline $\boldsymbol{J}$ & $6 \cdot 4182$ & 0.9712 & 0.9758 \\
\hline $\boldsymbol{I}$ & $6 \cdot 8471$ & 0.9692 & 0.9797 \\
\hline $\boldsymbol{H}$ & $7 \cdot 9033$ & 0.9384 & 0.9719 \\
\hline$G$ & $10 \cdot 8259$ & 0.9199 & 0.9984 \\
\hline
\end{tabular}

The general results as regards the different measures of expansion with which the steam was used are: 1 st. That with saturated steam, steam jacketing allows a greater gain to be realized with large measures of expansion than can be had without steam jacketing. In other words, expansion can beneficially be carried farther with steam jacketing than without. 2d. That with steam jacketing under the conditions of these experiments the total horse-power is obtained with slightly increasing economy as the measure of expansion increases; but that, on the contrary, a small economic loss is experienced as regards the net horse-power with each increase of the measure of expansion beyond about $5 \frac{3}{4}$ times.

Without steam jacketing and using saturated steam, an economic loss was sustained for both the total and the net horse-power, small for the first and large for the last, when the measure of expansion was increased from 7.9033 to 12.3978 times.

In connection with steam jacketing and different measures of expansion, it will be observed that the per centum of the steam evap- 
orated in the boiler, condensed in the steam jackets, increased regular ${ }_{y}$ as the measure of expansion increased, rising from $4 \cdot 6050$ per centum when the steam was expanded $5 \cdot 7037$ times (experiment $L$ ) to $6 \cdot 4641$ when the steam was expanded 10.8259 times (experiment $G$ ). This was as it should be, the greater cylinder refrigeration accompanying the greater measure of expansion, must necessarily draw from the steam jackets a greater proportion of heat. The fact that the jackets furnish a reservoir of heat for counteracting the greater cylinder refrigeration due to the greater measures of expansion, allows these greater measures to be more economically beneficial with steam jacketing than without it, as shown by the experiment.

The results of these experiments show that, as regards economy of fuel, there is no gain in a variable cut-off actuated by the governor of the engine between the limits of expansion employed. The variable cut-off in these cases was only useful for the graduation of the power which it probably accomplished somewhat more promptly than could have been effected by connecting the governor with a throttle valve.

It is necessary to here caution the reader that the condition of constant piston speed in the same cylinder, under which these experiments were made, is exceptionally favorable for obtaining relatively the highest economic results for the greater measures of expansion. This uniformity of piston speed was maintained by the action of the spare duplicate engine connected on the same shaft and supplying the complement of power for equal speed, let the power of the experimental engine vary as it might owing to the variations in the measures of expansion with which the steam of the same boiler pressure was used.

In regular practice, with the same cylinder, a constant boiler pressure, and a constant load, the piston speed decreases as the measure of expansion increases, because the piston pressure becomes correspondingly less and less. The weight of stean condensed in the crlinder per hour in addition to the condensation due to the development of the total power, and caused by the variations in the temperature of the interior metallic surfaces of the cylinder during a stroke of the piston, being nearly constant in these eases, while the weight of steam evaporated per hour in the boiler is smaller and smaller as the power becomes smaller and smaller, the steam condensed in the cylinder bccomes necessarily a larger proportion of the steam evaporated in the boiler, and the cconomy of the performance correspondingly decreases 
with every increase in the measure of expansion. Had the experiments been made under these unavoidable conditions of regular practice, the economic results of the greater measures of expansion would have been much less than they were. 'There would have probably been some loss in economic effect for the total horse-power, and certainly a marked loss for the net horse-power in all the cases where the measure of expansion exceeded the lowest employed, namely : $5 \cdot 7037$ times. If we seek to preserve the economic effect of the higher measures of expansion when a constant piston speed is maintained, by preserving that speed in a cylinder of corresponding size to give the same development of power with constant load and the same boiler pressure, there still results the larger condensation of steam per hour in the larger cylinder due to the greater extent of. its interior surfaces.

Of the economy due to steam of the boiler pressure in the cylinder jackets and piston. To ascertain the economic gain due to steam jacketing the cylinder and piston with steam of the boiler pressure, the cost of the total horse-power must be compared in the case of the jacketing with the similar cost in the case of no jacketing, taking care that in both cases the initial steam pressure on the piston and the mean back pressure against it, the measure of expansion with which the steam was used, the speed of the piston, and the total horsepower developed by the engine, are about the same.

For the determination without steam in the cylinder jackets and piston, we have the mean of experiments $B$ and $C$, giving for the initial pressure on the piston 71.0445 pounds per square inch above zero, for the back pressure against the piston 3.1170 pounds per square inch above zero, for the measure of expansion with which the steam was used 7.9033 times, for the speed of the piston $49 \cdot 2003$ double strokes per minute, and for the total horse-power developed. $144 \cdot 0238$.

For the determination with steam in the cylinder jackets and piston, we have the results of the comparable experiment $H$ in which the initial pressure on the piston was 71.2090 pounds per square inch above zero, the back pressure against the piston 3.1599 pounds per square inch above zero, the measure of expansion 7.9033 times, the speed of the piston 51.0981 double strokes per minute, and the total horse-power $151 \cdot 5674$.

The mean of experiments $B$ and $C$ gave for the cost of the total horse-power 25882.4317 units of heat consumed per hour. ExperiWhole No. Vol. CXI.-(Third Series, Vol. lxxxi.) 

In experiments $G$ and $H$ there were drained from the cylinder jackets alone $\left(\frac{5 \cdot 1224+4 \cdot 7990}{2}=\right) 4.9607$ per centum of the water vaporized in the boiler; and from the piston alone $\left(\frac{1 \cdot 3417+1 \cdot 2254}{2}=\right)$ 1.2835 per centum of the water vaporized in the boiler, making a total of $(4 \cdot 9607+1 \cdot 2835 \Rightarrow) 6 \cdot 2442$ per centum, of which roundly onefifth was contributed by the piston and four-fifths by the cylinder jackets, being almost exactly in the proportion of the steam jacketed surfaces of the piston to the steam jacketed surfaces of the cylinder, showing that per unit of surface the jacketing of the piston gave about the same condensation as the jacketing of the cylinder.

If, from the weight of feed water pumped into the boiler in experiment $H$ there be deducted the weight of water of condensation drained from the cylinder jackets and piston, there will remain $2448 \cdot 4284$ pounds of water which entered the cylinder per hour in the form of steam containing $2760609 \cdot 1421$ units of heat, so that the total horse-power in that experiment cost 18213.7395 units of heat exclusive of the units in the steam supplying the cylinder jackets and piston.

Comparing this result with the mean cost of the total horse-power in units of heat consumed per hour during experiments $B$ and $C$ $(25882 \cdot 4317$ units), in which there was no steam in the cylinder jackets and piston, there is found an economic gain of

$$
\left(\frac{25882 \cdot 4317-18213 \cdot 7395 \times 100}{25882 \cdot 4317}=\right)
$$

$29 \cdot 6290$ per centum for the steam jacketing, showing that the condensation in the steam cylinder during experiments $B$ and $C$ exceeded that in experiment $H$ by at least 29.6290 per centum of the feed water pumped into the boiler. The economy effected by the steam jacketing resulted entirely from this great lessening of the enormous cylinder condensation which always takes place in small cylinders using saturated steam with large measures of expansion.

In experiment $H$ a condensation in the steam jackets of 6.0244 per centum of the stean evaporated in the boiler prevented a condensation in the cylinder of 29.6290 per centum of the water evaporated in the boiler. This condensation in the jackets included not only the heat imparted to the interior surfaces of the cylinder, but also the heat lost by radiation from the exterior surfaces of the cylinder jackets. As 
these latter, however, were thoroughly protected by a covering of nonconducting materials, the loss from that cause must have been quite insignificant; but, whatever it was, a part of it should be deducted from the 6.0244 per centum, because, had there been no steam jackets, there would have been some, but less, radiation from the exterior surfaces of the cylinder; less, because the exterior surfaces of the cylinder and the steam pressure within it are less than for the jackets.

Again, under the conditions of ordinary practice, the steam jacketing would have given a slightly greater economy than in these experiments, because, in that case, the water of condensation from the jackets is delivered directly into the boiler with nearly the temperature of the steam in the latter having lost therein only its latent heat; while, in the case of the experiments, this water of condensation was cooled down to about the feed water temperature by being drained into measuring tanks before retuming to the boiler. In experiment $H$, every pound of the water of condensation drained from the jackets thus lost about 231 units of heat; had this been saved, as it might be in regular practice, the economic gain by the steam jacketing would have been increased 1.23 per centum, so that the true gain in fuel in regular practice due to the presence of steam in the cylinder jackets and piston would have been about 26.5 per centum.

It must not be supposed that this gain is absolute and the same for all steam engines; on the contrary, it is relative to the type of engine, to the proportions of the cylinder, to the dimensions of the cylinder, to the initial pressure on the piston and the back pressure against it, to the measure of expansion with which the steam is used, to the degree of superheating the steam may possess on entering the cylinder, to the proportion of water entrained by the steam, and to the speed of piston. In brief, the gain due to steam jacketing is affected by all the causes which affect the condensation of steam in the cylinder other than the condensation due to the transmutation of the heat, thus set free, into the total horse-power developed by the expanding steam alone.

Different types of engine require, for the same cylinder, different space in the clearance and in the steam passage; they also allow a different proportion of the exterior of the cylinder to be utilized for jackets. Thus, with the same dimensions of cylinder, the area of steam jacketing may be less, and the area of the internal surface of the cylinder, including surfaces of clearance and steam passage, more with 
one type than with another, in which case steam jacketing would be less economical than in the reverse case. Other things equal, the proportions of cylinder which diminish the gain due to steam jacketing are those which enclose a given space with the least superficies; for then a given mass of steam is exposed to the least condensing surface. The larger the dimensions of the cylinder, other things equal, the less the gain by steam jacketing, because the mass of steam increases as the cube of the dimensions, while its enclosing or condensing surface increases as the square only. The less the difference, other things equal, between the initial pressure on the piston and the back pressure against it, the less will be the gain by steam jacketing, as this difference is one of the causes of cylinder condensation. The greater the degree of superheating possessed by the steam, other things equal, the less will be the gain due to steam jacketing, because there will be less cylinder condensation for the jacket to act on. With a degree of superheating sufficient to prevent condensation, steam jacketing would be nugatory. The greater the proportion of water entrained by the steam, the greater will be the economic gain by steam jacketing, for the presence of water in the cylinder greatly increases the cylinder condensation, as it has to be boiled off during the expansion and the exhaust strokes largely by heat taken from the metal of the cylinder, and this deficit must be restored by the entering steam which to that extent undergoes condensation. The greater the speed of the piston, other things equal, the less will be the gain by steam jacketing; for, although the weight of steam condensed per hour, in the same cylinder, under this condition, may be nearly the same with all speeds of piston within practical limits, yet as the mass of steam passing through the cylinder in a given time will be in direct proportion to the piston speed, the cylinder condensation will be correspondingly reduced in proportion to the boiler exaporation; for example, if, with a given speed of piston, the condensation was 20 per centum of the steam evaporated in the boiler, then, with the piston speed doubled, this condensation would fall to 10 per centum, provided always that the metal of the cylinder transmitted the jacket temperature to the interior surfaces of the cylinder as rapidly as the steam came upon them. If this transmission was slower, then the reduction in the per centum of the condensation would not be so great.

Of the economy due to steam of the boiler pressure in the cylinder jackets alone - not in the piston. We have already ascertained the 

directions, about equal, and small, show them to result from errors of observation, and, as they neutralize each other, the conclusion is warranted that the addition of the steam jacketed surfaces of the piston to those of the cylinder produced no sensible effect. As a corollary to this there follows that the cylinder jackets alone were efficient enough to prevent all or nearly all the cylinder condensation, leaving the piston jackets nugatory.

We are here met with the fact that the weight of water of condensation drained from the piston and from the cylinder jackets in experiment $G$ have the relation of 1.0000 to $3 \cdot 8179$, and in experiment $L$ the relation of $1 \cdot 0000$ to $3 \cdot 6539$, showing a greater abstraction of heat per unit of surface from the piston than from the cylinder jackets, and this heat must have been transferred to something. Now, as the experiments show it was not used to prevent cylinder condensation, it must have been conducted away by the piston-rod which was in metallic contact with the piston, extending from the latter in both directions through both ends of the cylinder, and thence into the free air, one end of the piston-rod being in metallic contact with a crosshead. This rod undoubtedly transferred the heat from the piston jackets to the external air, and thus caused the observed condensation of steam within them.

Railway Alarm-Whistle. - In order to prevent a train passing a danger signal during a fog or snow-storm without being seen by the engineer, the Southern Railway Company of France have attached to the locomotive a steam whistle, which is controlled by the signal. The whistle is connected with an insulated metallic brush placed under the engine. Between the rails there is a projecting contact bar, faced with copper, which is swept by the brush when the train passes. This contact piece is connected with the positive pole of a voltaic battery, the negative pole of which is in communication with a commutator on the signal post, from which a wire leads to the ground. When the signal is "line clear" the passage of the brush over the fixed contact produces no result; but when the signal marks "danger," the commutator brings the negative pole of the battery in direct communication with the ground, and when the brush passes over the contact the completion of the electric current causes the whistle to be sounded, so as to alarm the driver.-L'Ingen. Univ. 